\title{
Novel phthalonitrile derivatives as potential compounds for extraction and complexation of metal cations
}

\author{
B. Mellah, ${ }^{1}$ M. Hidri, ${ }^{2}$ O. Naouali, ${ }^{3}$ N. Hamdi ${ }^{2,4}$ and L. Baklouti ${ }^{3,4}$ \\ ${ }^{1}$ National Center of Researches in Material Sciences (CNRSM), Borj CedriaTechnopark, BP 73, 8027 \\ Soliman,Tunisia. \\ ${ }^{2}$ Heterocyclic and Organometallic Chemistry Laboratory, Higher Institute of Environmental Sciences and \\ Technology, University of Carthage, Hammam-Lif, 2050, Tunisia. \\ ${ }^{3}$ Laboratory of Applied Chemistry and Natural Substances Resources and Environment, Faculty of Sciences, \\ University of Carthage, Zarzouna-Bizerte, 7021, Tunisia. \\ ${ }^{4}$ Chemistry Department, College of Science and Arts, Qassim University, Al-Rass, 58883, Kingdom of Saudi \\ Arabia \\ Corresponding author: bakloutilassaad@yahoo.fr
}

\section{ABSTRACT}

The synthesis and the binding properties of novel phthalonitrile derivatives 1-3 towards metal cations have been described in this paper. The complexation and extraction of some transition and heavy metal cations have been followed by UVvisible spectrophotometry absorption in methanol. The conductivity studies have been used in order to confirm complex's stoichiometries. The treatment of UV spectra by digital program showed the formation of $\mathrm{ML}$ (with $\mathrm{ML}_{2}$ in some cases) $(\mathrm{M}=$ metal, $\mathrm{L}=$ ligand) species. Beyond the discussion of the stability profiles of complexes particular attention is paid to the selectivity towards $\mathrm{Cu}^{2+}$ in the 1 st sequence of transition metal cations and towards $\mathrm{Hg}^{2+}$ in the sequence of heavy metal cations.

\section{Indexing terms/Keywords}

Phthalonitriles, cation binding properties, selectivity, complexation, extraction.

\section{Academic Discipline And Sub-Disciplines}

Organic and organometallic chemistry

\section{SUBJECT CLASSIFICATION}

Organic chemistry

\section{Council for Innovative Research}

Peer Review Research Publishing System

\section{Journal: Journal of Advances in Chemistry}

Vol. 11, No. 10

www.cirjac.com

editorjaconline@gmail.com, editor@cirjac.com 


\section{INTRODUCTION}

Since a long time, pharmaceutical industry required green chemistry to find new compounds able to copy the metalloenzymes and to find a better way to mimic their reactions. Continuous challenge of researches is devoted in this way to create new and efficient complexes. Among nitrile compounds, phthalonitriles are known as good candidates for the complexation of metal cations. They are also thermally stable with high performance composite structures. Besides, they constitute a class of high-temperature polymers that has a number of exceptional properties such as outstanding thermal and thermo-oxidative stability, good moisture resistance and superior fire resistance. [1-12]

As a continuation of our interests in phthalonitriles [13-15], we report here the synthesis, complexation and extraction properties of novel phthalonitriles 1-3 towards transition and heavy metal cations. The three compounds were prepared by Hamdi et coll.[16] The studies were performed by UV-visible spectrophotometry absorption and by conductometry. The last technique was used in order to test some stoichiometries of complexes formed. The liquid - liquid extraction of metallic picrate salts by ligands $\mathbf{1}$ - $\mathbf{3}$ were followed from water into dichloromethane.<smiles>Cc1cc(C)c(Nc2ccc(C#N)c(Cl)c2)c(C)c1</smiles><smiles>N#Cc1ccc(Oc2ccc(C=O)cc2)cc1C#N</smiles>

1<smiles>COc1ccc(CCOc2ccc(C#N)c(C)c2)cc1C</smiles>

Scheme 1: SSttucture of studied phthalonitriles derivatives 1-3.

\section{Results and discussion}

\section{Synthesis}

\section{Synthesis of 1}

4- nitrophthalonitrile $(0.38 \mathrm{~g}, 1.92 \mathrm{mmol}), 2.4 .6$ Trimethylphenylamine $(0.55 \mathrm{~g}, 1.92 \mathrm{mmol})$ and anhydrous $\mathrm{DMF}(15 \mathrm{~mL})$ were added to a round bottom flask under a nitrogen atmosphere. A fine powder of anhydrous potassium carbonate ( 0.8 $\mathrm{g}, 5.76 \mathrm{mmol}$ ) was added to this mixture. The resulting mixture was then heated to $80{ }^{\circ} \mathrm{C}$ in an oil bath under a nitrogen atmosphere for 6 hours. The crude product was collected by filtration and washed with distilled water. The crude product was recrystallized from THF-petroleum ether to afford a white powder. Yield: $0.77 \mathrm{~g}(98 \%)$. M.p. $=400{ }^{\circ} \mathrm{C}$. IR ( $\mathrm{KBr}$ pellet) $\mathrm{V}_{\max } \mathrm{cm}^{-1}: 1305(\mathrm{C}-\mathrm{N}), 1568(\mathrm{C}=\mathrm{C}), 2235(\mathrm{C} \equiv \mathrm{N}), 3049\left(\mathrm{C}-\mathrm{H}\right.$, aromatic). ${ }^{1} \mathrm{H}$ NMR (DMSO- $\left.\mathrm{d}_{6}\right): 8.38-8.98(\mathrm{~m}, 5 \mathrm{H}, \mathrm{Harom})$, $6.57\left(\mathrm{~s}, 2 \mathrm{H}, \mathrm{H}_{3}, 5^{\prime}\right), 4.21(\mathrm{~s}, 1 \mathrm{H}, \mathrm{NH}), 2.09\left(\mathrm{~s}, 3 \mathrm{H}, \mathrm{CH}_{3}\right), 2.02\left(\mathrm{~s}, 3 \mathrm{H}, \mathrm{CH}_{3}\right), 2.08\left(\mathrm{~s}, 3 \mathrm{H}, \mathrm{CH}_{3}\right)$. Anal. Calc. for $\mathrm{C} 28 \mathrm{H} 14 \mathrm{~N} 2 \mathrm{O} 2: \mathrm{C}$, 78.135\%; H, 5.786; N, 16.080, Found: C, 78.1; H, 5.6; N, $16.0 \%$

\section{Synthesis of 2}

The synthesis of 2 was similar to 1, except 4-Hydroxybenzaledhyde $(1.27 \mathrm{~g}, 5.77 \mathrm{mmol})$ was employed instead of 2.4 .6 Trimethylphenylamine. The amounts of the other reagents were: 4-nitrophthalonitrile $(1 \mathrm{~g}, 5.8 \mathrm{mmol})$ and anhydrous potassium carbonate $(2 \mathrm{~g}, 13.88 \mathrm{mmol})$. Yield: $1.12 \mathrm{~g}(76 \%)$ M.p. $=350{ }^{\circ} \mathrm{C}$. IR spectrum $\left(\mathrm{cm}^{-1}\right): 1263(\mathrm{C}-\mathrm{O}-\mathrm{C}), 1568$ $(\mathrm{C}=\mathrm{C}), 2236(\mathrm{C}=\mathrm{N}), 3049\left(\mathrm{C}-\mathrm{H}\right.$, aromatic). ${ }^{1} \mathrm{H}$ NMR (DMSO-d $)$ : $9.1(\mathrm{~s}, 1 \mathrm{H}, \mathrm{CHO}), 7.1-7.77\left(\mathrm{~m}, 8 \mathrm{H}, \mathrm{H}_{\mathrm{ar}}\right)$. Anal. Calc. for C28H14N2O2: C, 72.576; H, 3.248; N, 11.285, Found: C, 72.4; H, 3.1; N, 11.1\%.

\section{Synthesis of 3}

The synthesis of $\mathbf{3}$ was similar to 1, 2-(3,4-diméthoxyphenyl)ethanol was employed instead of 2.4.6 Trimethylphenylamine. The amounts of the other reagents were 4-nitrophthalonitrile, $1 \mathrm{~g}(5.55 \mathrm{mmol})$ and anhydrous potassium carbonate, $2 \mathrm{~g}$ (13.88 mmol). Yield: $0.77 \mathrm{~g}(85 \%)$ M.p. $=370^{\circ} \mathrm{C}$. IR spectrum $\left(\mathrm{cm}^{-1}\right): 3077(\mathrm{Ar}-\mathrm{CH}), 2227(\mathrm{C}-\mathrm{N}), 1601(\mathrm{C}-\mathrm{C}), 836,797(\mathrm{C}-$ F) : 1263 (C-O-C), 1568 (C=C), $2227(\mathrm{C} \equiv \mathrm{N}), 3049\left(\mathrm{C}-\mathrm{H}\right.$, aromatic). ${ }^{1} \mathrm{H}$ NMR (DMSO-d $)$ : 6.50-7.6(m, 6H, Har), 3.74(s, 6H, $\mathrm{OCH}_{3}$ ) , $2.86\left(\mathrm{t}, 2 \mathrm{H}, \mathrm{CH}_{2}\right), 4.1\left(\mathrm{t}, 2 \mathrm{H}, \mathrm{CH}_{2}\right)$, Anal. Calc. for C28H14N2O2: C, 70.117; H, 5.230; N, 9.085, Found: C, 70.1; $\mathrm{H}, 5.2 ; \mathrm{N}, 9.0 \%$.

\section{Instrumentations}

The spectrophotometric and conductometric studies were followed in methanol (Riedel-de Haën for HPLC) and the dichloromethane (Fluka, Purum) used in extraction, were commercial and used without further purification. The metal salts chosen were chlorides (Fluka, Purum) and were dried under vacuum for at least $24 \mathrm{~h}$ before use. The concentrations of the stock solutions of cations were standardized by complexometry using the appropriate colored indicators [17]. The UV absorption spectra were recorded on a Perkin Elmer Lambda 11 spectrophotometer. The supporting electrolyte used in the stability constant determinations was $\mathrm{NEt}_{4} \mathrm{Cl}$ (Acros Organics) according to the procedure already described [18]. The 
picrate salts employed in extraction were prepared as described in literature [19]. A conductivity measurement was made by using Cyber Scan PC510 conductivity meter. The conductivity cell constant is $\mathrm{K}=0.9 \mathrm{~cm}$.

Melting points were determined using an Electrothermal apparatus and are uncorrected. ${ }^{1} \mathrm{H}$ NMR spectra were carried on a Varian Gemini $400(400 \mathrm{MHz})$ spectrometer using TMS as internal standard $(\delta=0 \mathrm{ppm})$. IR spectra were recorded on a Perkin - Elmer 398 Spectrophotometer. Elemental analyses were performed on Perkin - Elmer 2400 elemental analyzer, and the values found were within $\pm 0.3 \%$ of the theoretical values.

\section{Complexation by UV - visible spectrophotometer}

The stability constants $\beta x y$ being the concentration ratio $\left[\mathrm{M}_{x} \mathrm{~L}_{y}{ }^{\mathrm{xn}+}\right] /\left(\left[\mathrm{Mn}^{+}\right]_{x}[\mathrm{~L}]_{y}\right)$ (where $\mathrm{Mn}^{+}=$Metal ion and $\mathrm{L}=\mathrm{Ligand}$ ) were determined by UV-absorption spectrophotometry at $25^{\circ} \mathrm{C}$. The addition of the metal salts to the ligand induced generally spectra changes, large enough to allow the analysis of the resulting data using the program "Letagrop" [20]. Best values for the formation constants $\beta x y$ of the various complex species and their molar absorptive coefficients for various wavelengths, are deduced from the best fit between the experimental and calculated UV spectra. The best fit is reflected by the lowest value of $U$ (the sum of $U$ values for all given lambda) corresponding to the square sum of a differences between experimental and calculated absorbances $\left(U=\Sigma\left(A_{c a l}-A_{\text {exp }}\right)^{2}\right)$. The $\beta x y$ values correspond to the average of at least three independents experiments [20, 21].

The UV absorption spectra have been recorded between 220 and $360 \mathrm{~nm}$. The free phthalonitriles 1-3 absorption spectra exhibit one maximum of absorption at 285,308 and $310 \mathrm{~nm}$, respectively. One shoulder at $255 \mathrm{~nm}$ for 1 and at $280 \mathrm{~nm}$ for 2 and $\mathbf{3}$ is also observed. The complexation of metal cations by these ligands is expressed by a variation of spectra. In fact, the titration is interpreted by both a decrease of absorbance and a light hypsochromic displacement of the maximum of absorption in all cases of Metal/Ligand systems $(\Delta \lambda \approx 3 \mathrm{~nm})$. The end of interaction between the phthalonitriles and cations is shown by the superposition of the spectra at around a ratio $R\left(R=C_{M} / C_{L}\right)$ equals to 8 . In the case of $A g^{+} / 1$, $\mathrm{Hg}^{2+} / 2$ and 3 , isobestic points are clearly observed.

Furthermore, the treatment of these spectra by the digital program [20] illustrates the stoichiometries of different complexes formed and respectively their stability constants. The results are collected on table 1 for transition metal cations and on table 2 for heavy metal cations. The complexes formed in all cases are ML. However, in the case of $\mathrm{Cu}^{2+}$ and $\mathrm{Zn}^{2+}$, two complexes $\mathrm{ML}$ and $\mathrm{ML}_{2}$ were found with ligand 3. For $\mathrm{Pb}^{2+} / 2-3$ and $\mathrm{Mn}^{2+} / 1-3$ the variations of spectra are very small to not enable their treatments by the program Letagrop.

Table 1: Complexation of transition metal cations by 1-3 in methanol, at $25^{\circ} \mathrm{C}, \mathrm{I}=10^{-2} \mathrm{~mol}^{-\mathrm{L}^{-1}}$.

\begin{tabular}{|c|c|c|c|c|c|c|}
\hline & $M: L$ & $\mathrm{Mn}^{2+}$ & $\mathrm{Co}^{2+}$ & $\mathrm{Ni}^{2+}$ & $\mathrm{Cu}^{2+}$ & $\mathrm{Zn}^{2+}$ \\
\hline 1 & $1: 1$ & a & 3.45 & 4.12 & 4.76 & 3.42 \\
\hline 2 & $1: 1$ & $a$ & 2.80 & 3.60 & 4.05 & 3.56 \\
\hline \multirow{2}{*}{3} & $1: 1$ & \multirow{2}{*}{ a } & \multirow{2}{*}{3.34} & \multirow[t]{2}{*}{3.44} & 3.87 & 3.73 \\
\hline & 1:2 & & & & 7.32 & 6.98 \\
\hline
\end{tabular}

a: Absorbance changes too small to enable satisfactory fitting.

$0.01<\sigma_{N-1}<0.2$

Table 2: Complexation of heavy metal cations by 1-3 in methanol, at $25^{\circ} \mathrm{C}, \mathrm{I}=10^{-2} \mathrm{~mol}^{-\mathrm{L}^{-1}}$.

\begin{tabular}{|c|cccc|}
\hline & $\mathbf{M : L}$ & $\mathbf{H g}^{2+}$ & $\mathbf{P b}^{2+}$ & $\mathbf{A g}^{+}$ \\
\hline $\mathbf{1}$ & $\mathbf{1 : 1}$ & 4.78 & 4.09 & 3.12 \\
\hline $\mathbf{2}$ & $\mathbf{1 : 1}$ & 4.00 & $\mathrm{a}$ & 3.41 \\
\hline $\mathbf{3}$ & $\mathbf{1 : 1}$ & 3.89 & $\mathrm{a}$ & 3.09 \\
\hline
\end{tabular}

a: Absorbance changes too small to enable satisfactory fitting.

$0.01<\sigma_{N}-1<0.06$

As regards to the complexes $\mathrm{ML}$ in the $1^{\text {st }}$ sequence of transition metal cations, the stability constants shift between 2.80 and 4.76 logarithmic units. The highest value is in favor of $\mathrm{Cu}^{2+}$ with ligand 1 which leads to a selectivity of this ligand towards $\mathrm{Cu}^{2+}\left(\mathrm{S}_{\mathrm{Cu}^{2+}} \mathrm{C}_{\mathrm{o}}{ }^{2+}=26\right)$. Another selectively is detected with ligand 2 towards $\mathrm{Cu}^{2+}$ with an approximate value $\mathrm{S}$ $\mathrm{Cu}^{2+} / \mathrm{co}^{2+}$ equals to 18 . The profiles of stability of ML (figure 1) illustrate the resemblance of the stability sequence of high spin octahedral metal complexes with the Irving-Williams rules which is translated by the increase of the complex stability from $\mathrm{Mn}^{2+}$ to $\mathrm{Cu}^{2+}$ and then a decrease to $\mathrm{Zn}^{2+}$. Furthermore, the complexes $\mathrm{ML}_{2}$ in the case of $\mathrm{Cu}^{2+}$ and $\mathrm{Zn}^{2+}$ with ligand 3 are less stable than their corresponding ML. Their stability constants are equal to 3.45 and 3.25 logarithmic units, respectively. In the case of heavy metal cations, $\mathrm{Hg}^{2+}$ is more interacted by the three derivatives 1-3 and the best value of stability constants is 4.78 logarithmic units found with $\mathbf{1}$. Comparing between the three phthalonitriles, 1 seems to have more affinity towards transition and heavy metal cations. In both case of series of metal cations, complexes $\mathrm{ML}$ formed by ligand $\mathbf{1}$ are more stable than with $\mathbf{2}$ and $\mathbf{3}$ and even more stable than $\mathrm{ML}_{2}$. The presence of nitrile functions and nitrogen 
on the bridge between the two aromatic units seems to increase the affinity of ligand 1 . The triple bond between $\mathrm{N}$ and $\mathrm{C}$ atoms extends aromaticity and then leads to a higher interaction between the ligand 1 and the cation. Moreover, the soft character of both nitrogen atom and aromatic units could be the reason of the high interaction with soft acid as transition and heavy metal cations according to Lewis.

Fig

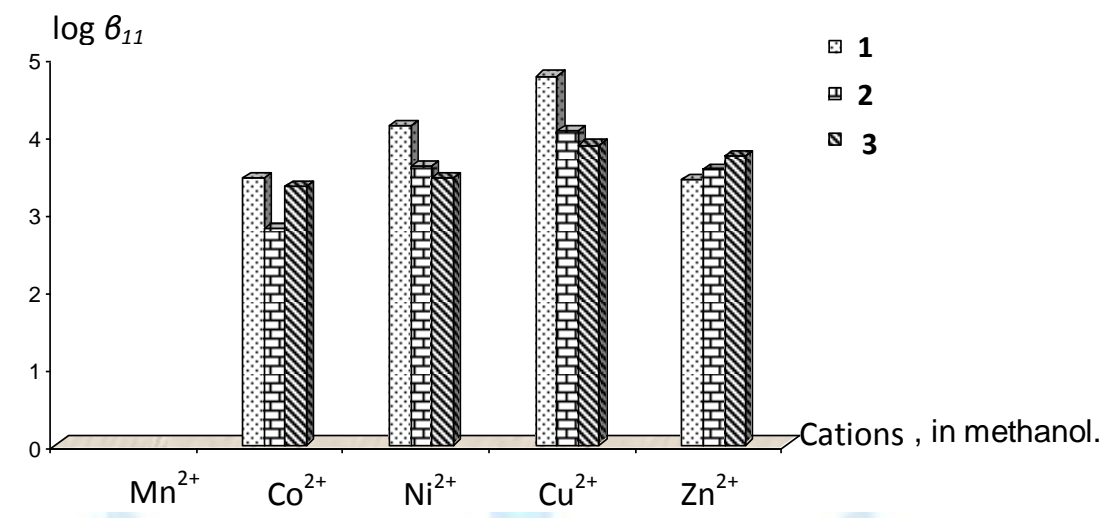

\section{Complexation by conductometry}

The present work proposes a simple, accurate and low-cost method employing conductometric detection during the complexation titration using metal cation chloride as titrant. The process was based on the chemical interaction between cation coming from chloride ions and phthalonitriles 1-3. Under optimized experimental conditions the method was applied for some cases of systems Metal/Ligand which created previously some difficulties in their treatments in UV-visible spectrophotometer absorption studies.

This method is carried on by the projection of the meeting point of the slopes corresponding to the variation of conductance values via the ratio $R=C_{M} / C_{L}$ according to the literature. $[29,30]$ The results obtained are in close agreement with those obtained using the first technique. Only system $\mathrm{Cu}^{2+} / 3$ (figure 2) is presented here. In fact, the titration of the solution of phthalonitriles 3 by a solution of $\mathrm{CuCl}_{2}$ shows a variation of conductance values, proportionally to the ratio $R=C_{M} / C_{L}$. After plotting the conductance values, variation of the curve was observed and the projection of the meeting point of the slopes corresponds to the stoichiometry of the complex formed during the titration. In the case of $\mathrm{Cu}^{2+} / 3$, complexes $\mathrm{ML}$ and $\mathrm{ML}_{2}$, as shown on figure 2, are formed simultaneously.

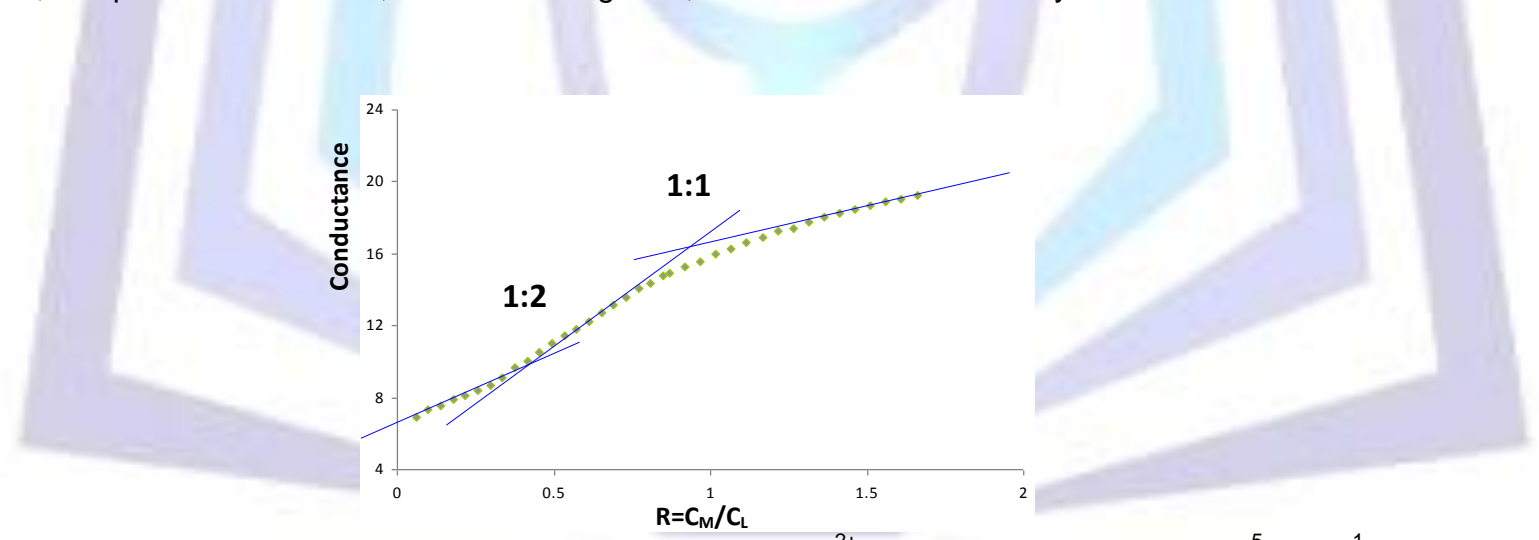

Figure 2: Conductometric titration of 3 by $\mathrm{Cu}^{2+}$ in methanol, $\mathrm{C}_{\mathrm{L}}=3.88 \times 10^{-5} \mathrm{~mol}^{-\mathrm{L}^{-1}}$.

\section{Extraction studies}

The extraction experiments from water into dichloromethane were performed according to the following procedure: $5 \mathrm{~mL}$ of $2.5 \times 10^{-4} \mathrm{M}$ aqueous picrate solution and $5 \mathrm{~mL}$ of $2.5 \times 10^{-4} \mathrm{M}$ solution of ligand in $\mathrm{CH}_{2} \mathrm{Cl}_{2}$ were mechanically shaken in stoppered glass tube for $3 \mathrm{~min}$, then magnetically stirred in a thermoregulated water bath at $20 \pm 0.1^{\circ} \mathrm{C}$ for 30 min and finally left standing for a further $30 \mathrm{~min}$ in order to obtain a complet separation of the two phases. The absorbance A of the metal picrates remaining in the aqueous phase was then determined spectrophotometrically at $355 \mathrm{~nm}$. The percentage extraction, \%E, are derived from the expression $100\left(A_{0}-A\right) / A_{0}$, where $A_{0}$ is the absorbance of the aqueous solution of a blank experiment without phthalonitrile. [22]

The percentages of extraction \%E calculated are generally minor in all cases of cations, slightly improved for ligand $\mathbf{1}$, where \%E shifts between 4 and 36. This enhancement is probably due to the presence of $\mathrm{N}$ in addition comparing with 2 and 3. The highest value of \%E is in favor of $\mathrm{Cu}^{2+}(36 \%)$ and $\mathrm{Ag}^{+}(27 \%)$ The first result confirms once again the high affinity of this ligand towards $\mathrm{Cu}^{2+}$. While the second, towards $\mathrm{Ag}^{+}$, could be interpreted by the soft character of both base $\mathrm{N}$ and acid $\mathrm{Ag}^{+}$though this preference have not been seen in the complexation study. 


\section{Conclusion}

This review is dealing about the synthesis and the binding properties of new phthalonitriles derivatives 1-3 towards some transition and heavy metal cations. The UV spectrophotometric and conductometric studies illustrates the formation of complexes $\mathrm{ML}$, and $\mathrm{ML}_{2}$ in addition of $\mathrm{ML}$ in case of $\mathrm{Cu}^{2+}$ and $\mathrm{Zn}^{2+}$ with ligand 3 . Moreover, the profiles of stability of complexes $\mathrm{ML}$ is following the Irving-Williams rules and making evidence of the high stability of complexes of $\mathrm{Cu}^{2+} . \mathrm{A}$ selectivity $\mathrm{S}\left(\mathrm{Cu}^{2+} / \mathrm{Co}^{2+}\right)$ of 26 with 1 and 18 with 2 are detected. As regards to the stability, the presence of nitrogen atom in the bridge between the two units in ligand $\mathbf{1}$ seems to improve its affinity comparing with $\mathbf{2}$ and $\mathbf{3}$ carrying oxygen, a hard atom, in their structures.

\section{REFERENCES}

[1] Keller, T. M.; Price, T. R.; J. Macromol. Sci. Chem., 1982, A18, 931-917.

[2] Keller, T. M.; J. Polym. Sci. Part A Polym. Chem., 1988, 26, 3199-3212.

[3] Keller, T. M.; Polym. Commun.; 1987, 28, 337-339.

[4] Keller, T. M.; Polymer 1993, 34, 952-955.

[5] Keller, T. M.; Chem. Mater., 1994, 6, 302-305.

[6] Sastri, S. B.; Keller, T. M.; J. Polym. Sci. Part A Polym. Chem., 1998, 36, 1885-1890.

[7] Sastri, S. B.; Keller, T. M.; J. Polym. Sci. Part A Polym. Chem., 1999, 37, 2105-2111.

[8] Dominguez, D. D.; Jones, H. N.; Keller, T. M.; Polym. Compos., 2004, 25, 554-561.

[9] Keller, T. M.; Dominguez, D. D.; Polymer, 2005, 46, 4614-4618.

[10] Laskoski, M.; Dominguez, D. D.; Keller, T. M.; J. Polym. Sci. Part A Polym. Chem., 2005, 43, 4136-4143.

[11] Dominguez, D. D.; Jones, H. N.; Keller, T. M.; High Perform. Polym., 2006, 18, 283-304.

[12] Dominguez, D.D.; Keller, T.M; Polymer, 2007, 48, 91-97.

[13] Naouali, O.; Mellah, B.; Medyouni, R.; Hamdi, N.; Baklouti., L; European Journal of Chemistry; 2015, 6, 337- 341.

[14] Naouali O. , Frija R., Elgabsi W., Hamdi N., Baklouti L; Mediter J. Chem. 2014, 3, 1057-1065

[15] Naouali O., Boubakri L., Hamdi N., Baklouti L; Asian J. of Adv. Basic Sci.: 2014, 3, 186-193

[16] Naceur HAMDI et al., unpublished results

[17] Merck, E. (ed.): Méthodes d’Analyse Complexométrique avec le Titriplex. 3 Grafis, Darmstadt, 1992.

[18] Arnaud Neu, F. ; Schwing Weill, M.J. ; Ziat, K. ; Cremin, S. ; Harris, S.J.; McKervey, M.A.; New J. Chem., 1991, 15, 33-37.

[19] Pedersen, C.; J. Am. Chem. Soc., 1970, 92, 391.

[20] Sillen, G.; Warnquist, B. Ark. Kemi. 1968, 31, 377- 390.

[21] Casnati, A.; Pochini, A.; Ungaro, R.; Ugozzoli, F.; Arnaud, F.; Fanni, S.; Schwing, M. J.; Egberink, R. J. M.; Jong, F.; Reinhoudt, D. N. J. Am. Chem. Soc., 1995, 117, 2767- 2777.

[22] Pedersen, C. J. Am. Chem. Soc., 1970, 92, 386- 391. 